\title{
The Research on Decision Mechanism of Agricultural Products Logistics Transportation Based on Neural Network
}

\author{
Huang Xianjun ${ }^{1,2, *}$ \\ ${ }^{1}$ School of Management, Hefei University of Technology, Anhui, 230009, China; ${ }^{2}$ School of Economics and Manage- \\ ment, Anqing Normal University, Anhui, 246133, China
}

\begin{abstract}
In this paper, study the Logistics research status at home and abroad, analyze the importance of logistics transport to economic and business, as well as the three main problems in the logistics transport of agricultural products in China. On the basis of front, evaluation index of network transport is determined, as well as the optimization problem of transportation. Finally experimental results are presented, and the experimental results are analyzed. Experimental results show that the neural network can solve the transport problem, and it is very efficient.
\end{abstract}

Keywords: Agricultural products, Logistics transportation, Neural Network.

\section{INTRODUCTION}

In China in a few years after the start, the third party logistics although has obtained certain achievements, but with the world's developed countries of the third party logistics development level have certain gap, the overall effect is not obvious.It Is mainly due to the third party logistics enterprises in our country are mostly from the original transportation or warehousing enterprise change, disadvantages with the understanding of modern logistics is more a lack of operation experience of modern logistics. In transportation decision-making, service is not a scientific phenomenon. Therefore, in view of the third party logistics transportation decision-making research in depth has very important practical significance [1].

In this paper, study the Logistics research status at home and abroad, analysis the importance of logistics transport to economic and business, as well as the three main problems in the logistics transport of agricultural products in China. On the basis of front, evaluation index of network transport if determined, as well as the optimization problem of transportation. Finally experimental results are presented, and the experimental results are analyzed. Experimental results show that the neural network can solve the transport problem, and it is very efficient.

\section{THE IMPORTANCE, PROBLEMS AND RE- SEARCH STATUS OF LOGISTICS TRANSPORT}

\subsection{The Importance of Logistics Transport}

1) The important practical significance for enhancing supply chain management. According to the American Council of Logistics Management concept of supply chain management, supply chain management, including full program involving procurement, outsourcing, and other processes of transformation, management activities, and all logistics management activities. More importantly [2], it also includes coordination and collaboration with channel partners, involving suppliers, intermediaries, third-party logistics service providers and customers. This requires an effective supply chain management system to ensure the maximization of profits throughout the supply chain. In today's highly competitive, the first source of profit (the production of profits) and the second source of profit (sales profit) has not much profit. The third source of profit (profit Logistics) has become the profit of the entire supply chain, "black hole." Therefore, how to reduce supply chain logistics costs, mining third profit source of supply chain management has become the focus of research. From the perspective of reducing logistics costs, transport links in the logistics cost share is about $35 \%$ to $60 \%$ [3]. If we can reduce transportation costs, we can supply chain logistics system to improve efficiency and make a significant contribution, to maximize profits throughout the supply chain. Therefore, the management of transport logistics to ensure that transportation will undoubtedly become normal. Reduce transportation costs and effective supply chain management has become a key research.

2) The important practical significance for own development of third-party logistics companies. With the development of modern logistics, the movement of goods is becoming faster; operating range is becoming wider. Especially in the wave of economic globalization, driven logistics tentacles can be throughout the world. Under the new economic conditions, the third party logistics market competitive advantage will no longer matter how many resources of the business, and that it can mobilize, coordinate, and finally how much can integrate social resources to enhance their market competitiveness [4]. By studying the transport decisions, companies can choose the most suitable mode of transport, transport routes and optimize transportation networks to achieve lower costs, reduce errors, increase efficiency and improve service levels. 


\subsection{Research Status of Transportation and Distribution Logistics Network Optimization}

For quantitative optimization study abroad mainly in the logistics distribution network optimization based. The research process can be divided into three stages:

1) 1985 years, Bsetal [5] first line of each transport cost single distribution center quantitatively math; 1990 Klincewicz a mathematical model of this problem, the use of a concave function to calculate transportation costs, as well as the use of Tcs (consolidation terminals) were costing costs. However, these findings are not on the volume of goods to be considered, the model is relatively simple, can only solve relatively simple problems.

2) Hub location problems for the second phase of research are the study of logistics and distribution network. It was originally proposed by Kellyr [6], he proposed a mathematical model applied to LTL (less than truck load) transportation problems. Use small transport to transport goods to Tcs (transshipment centers), and use large-scale transport between TCs. Kellyand Lao and Aykin introduced direct transport model and a model for the transport of goods transport facility, which is the earliest emergence of logistics and distribution network planning.

3) Logistics and distribution network of the third phase of research is to model accurately calculate the transport of goods. In this process, we need to consider the weight and volume of the goods. Hall made studies in this respect of the first time [7]. In order to improve efficiency in the use of his vehicle, the weight and volume of cargo from the start, made a mathematical model. This model is suitable for LTL freight. In this case, the goods cannot be filled immediately; consumers have to pay the freight FCL. The mathematical model is closer to reality by Fleischmalin made in 1993. This model of reality in the transport of goods made systematic analysis.

\subsection{China's Agricultural Supply Chain Existing Prob- lems}

1) Missing Intensive and the union of the channel chain, and the unstable relationship between channel members

First, the main problem of the existence of the flow channel system of agricultural products is fragmented participating members, lack of integration, intensive and the union of the channel chain is missing. The main channels of agricultural products is scattered farmers, imperfect development of cooperative organizations and small-scale, a small number of enterprises. Due to the low level of organization in circulation (mainly for the circulation of the body's low level of organization, a low degree of organization of the distribution process, the low degree of organization of the flow of services), resulting in a lack of largescale agricultural distribution companies (Group) and thereby Intensive formed alliance of channel chain. Second, since most state separation between presentation and marketing of agricultural products circulation channel members, cannot form a close working relationship type, resulting in low levels of co-operative, channel relationships unstable [8].

\section{2) Agricultural supply chain service system is imperfect}

China's current agricultural supply chain service system consists of three levels: the first level is the production of the service layer, and the second level is the flow of the service layer, and the third level is the consumer services layer [9]. The main problem is that too much of its existence the main level of service at all levels within the system, the lack of synergy between. Serious institutional barriers exist in the supply chain. Wholesale services limited circulation, showing a "low degree of organization, form a single organization, communication and dull, trading backward, lack of strategic cooperation, poor circulation efficiency" and other features. Agricultural standardization system has failed to effectively and comprehensively promote the establishment, and thus meet the circulation of agricultural products for the modernization of key technologies has not yet been established. Various aspects of information technology and e-commerce applications lag. Government to establish a run agricultural supply chain service system is still a lack of overall co-ordination of macroeconomic planning. Thereby weakening the function of these largely supplies chain service system of play.

3) The lack of quality and safety of agricultural supply chain management system

Because our agricultural supply chain involved in the majority of inter-subjectivity "one-off sale" transaction process quality "double marginal increase" is serious. Various aspects only consider their own interests. Subjectivities are difficult to consider the mutual relations from long-term interests. Product quality and safety issues outstanding performance in all aspects of quality and safety of agricultural information is difficult to be effective records. Transmission and storage, is not conducive to quality and safety issues prior warning, interim monitoring and retroactively. This has resulted in the supply chain coupled to each other, it is difficult to form an effective quality and safety management system [10].

Fully visible, to create a new situation of China's agricultural products circulation, must change and innovation on existing agricultural supply chain system, the construction of modern agricultural supply chain management system.

\section{NEURAL NETWORK MODEL}

The so-called neural network is many single "neurons" linked together. Thus, a "neuron" output could be another "neurons" input. For example, the following diagram is a simple neural network Fig. (1):

We use circles to represent the input of the neural network; marked +1 circle is called the bias node, which is the intercept. Leftmost layer neural network called the input layer, the layer is called the rightmost output layer (in this case, only one output layer nodes). All nodes in the middle layer is called the hidden layer, because we cannot observe the training sample set their values. At the same time you can see, the example above neural network has three input units (not counting the bias unit), three hidden units, and an output unit.

Neural networks can also be a plurality of output units. For example, the following neural network has two hidden layer: L2 and L3. Output layer L4 has two output units Fig. (2). 


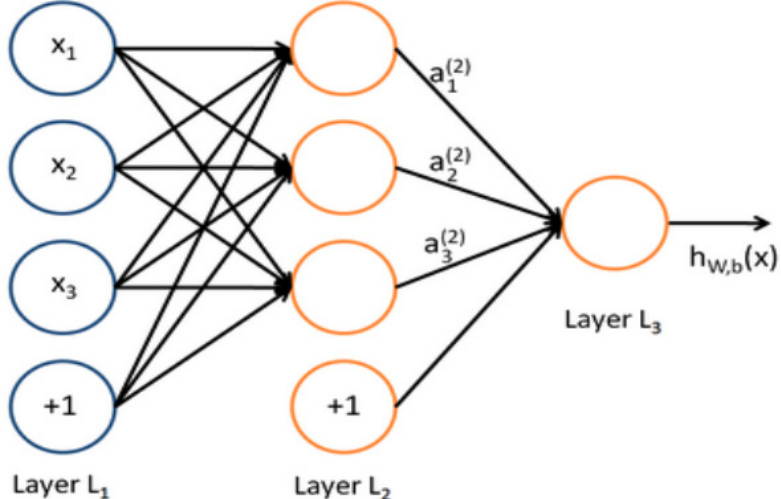

Fig. (1). General neural networks.

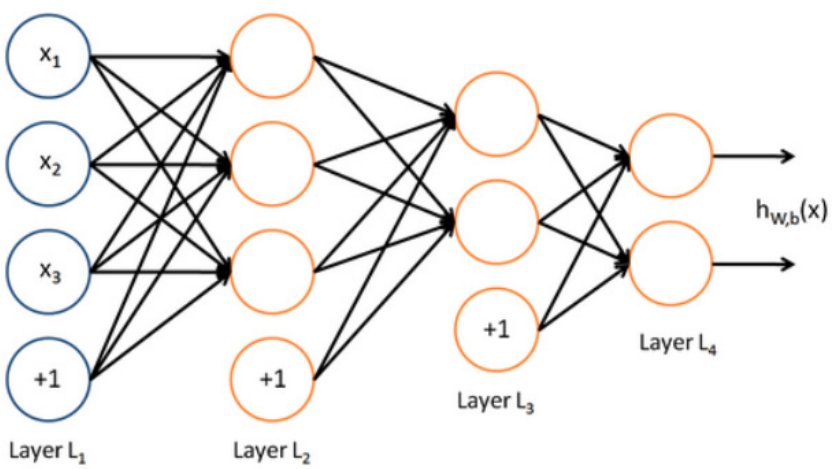

Fig. (2). Neural networks of multiple output units.

\section{COMPREHENSIVE EVALUATION METHOD OF THE DECISIONS OF CHOOSING LOGISTICS TRANSPORTATION MODE}

Target logistics system is to achieve goods fast, safe and low-cost transportation, namely transport speed, accuracy, security and economy. In reality, if the emphasis on speed, accuracy and security of transportation, the transportation costs will increase. Conversely, if the transportation costs, other transportation goals cannot be fully achieved. Therefore, the choice of transport mode should be considered a variety of targets for transport, comprehensive evaluation method

Comprehensive evaluation method in determining the mode of transport under the premise of the evaluation factors, according to the importance of these evaluation factors were given their respective weights, and then to comprehensive evaluation of different modes of transport.

\subsection{Determine Evaluation Indexes}

In the choice of mode of transport, to ensure the safety of transport is the primary condition of choice. It includes physical, equipment and safety of shipped goods. To ensure the safety of the goods being transported, should first understand the characteristics of goods being shipped, such as weight, volume, precious degree, internal structure and other physical and chemical properties (flammable, fragile, dangerous, etc.), and then select the secure transport the way. An important indicator of the transit time and the arrival time of transport is a measure of the effect of material transport. Transport costs is a measure of the effect of a comprehensive transportation standards, is the main factor affecting the logistics cost of the system.

In summary, the choice of mode, usually in the premise of ensuring transport safety, to measure the transit time and transportation costs. Then consider low-cost mode of transport when the arrival time is met. Therefore, decisionmaking can be used in four modes of transport safety evaluation indexes, rapid, convenience and economy.

\subsection{Quantitative of Evaluation Indexes}

Different evaluation indexes have different dimensions and dimensionless units. In order to eliminate the effect of dimension and dimensionless units, before decisions should first evaluation indexes dimensionless treatment. Through quantification calculations, the index values contain different dimensions of evaluation into a dimensionless value of a given region, the general choice of the number of mapped to $[0,1]$ range. So it could get rid of the impact of measurement units.

\section{1) Quantitative calculated of Safety (S)}

Transport safety, mainly refers to the full extent of the goods being transported by cargo damage rate to represent. Breakage rate is larger, the safety is worse; on the contrary, the better degree of safety.

$$
S=\max \left(\mathrm{S}_{1}, \mathrm{~S}_{2}, \mathrm{~S}_{3}, \mathrm{~S}_{4}, \mathrm{~S}_{5}\right)
$$

$S$ is the max value of the five kinds modes of transport. $\mathrm{S}_{1}$ is the railway transport safety. $\mathrm{S}_{2}$ is the highway transport safety. $S_{3}$ is the waterway transport safety. $S_{4}$ is the aviation transport safety. $S_{5}$ is the conduit transport safety.

Various modes of transport security, available relative value expressed as follows:

$\mathrm{S}_{i}=\frac{S}{S_{i}}, i=1,2,3,4,5$

\section{2) Quantitative calculated of Speed (S)}

Rapidity mainly for cargo from the shipper to the time required for receipt, that the transit time of goods. The shorter the time requires, the better the rapidity is. Conversely, the longer the time requires, the rapidly is worse.

$T=\min \left(\mathrm{T}_{1}, \mathrm{~T}_{2}, \mathrm{~T}_{3}, \mathrm{~T}_{4}, \mathrm{~T}_{5}\right)$

$T$ is the min time value needed of the five kinds modes of transport. $T_{1}$ is the time needed by railway transport. $T_{2}$ is the time needed by highway transport. $T_{3}$ is the time needed by waterway transport. $T_{4}$ is the time needed by aviation transport. $\mathrm{T}_{5}$ is the time needed by conduit transport.

Various modes of transport speed, available relative value expressed as follows:

$T_{i}=\frac{T}{T_{i}}, i=1,2,3,4,5$

\section{3) Quantitative calculated of Convenience (C)}

Various modes of transport convenience quantitative calculation is more difficult. In one case, you can use the ap- 
proximate location of the distance between the consignor loading (boats, aircraft) between locations to represent convenience. The closer the distance is, the better the convenience is.

$$
D=\min \left(D_{1}, D_{2}, D_{3}, D_{4}, D_{5}\right)
$$

$D$ is the min unloading distance of the five kinds modes of transport. $D_{1}$ is the unloading distance needed by railway transport. $D_{2}$ is the unloading distance needed by highway transport. $D_{3}$ is the unloading distance needed by waterway transport. $D_{4}$ is the unloading distance needed by aviation transport. $D_{5}$ is the unloading distance needed by conduit transport.

Various modes of transport unloading distance, available relative value expressed as follows:

$D_{i}=\frac{D}{D_{i}}, i=1,2,3,4,5$

\section{4) Quantitative calculated of economic (E)}

Economy characterized by savings, such as transport costs, handling costs, packaging costs, management fees, an so on. The less total expenses incurred during transport, the better economical as possible.

$$
E=\min \left(E_{1}, E_{2}, E_{3}, E_{4}, E_{5}\right)
$$

$E$ is the min cost of the five kinds modes of transport. $E_{1}$ is the cost of railway transport. $E_{2}$ is the cost of highway transport. $E_{3}$ is the cost of waterway transport. $E_{4}$ is the cost of aviation transport. $E_{5}$ is the cost of conduit transport.

\subsection{Determining the Weights}

In fact, for the characteristic mode of transport users have their special preferences. Some people focus on the economy. Some focus on quickness. Therefore, in order to evaluate the results more reasonable, the indicators must be given a certain number of rights. Set that $a_{1}, a_{2}, a_{3}, a_{4}$ are the weights of safety indicators, quickly type indicators, convenience indicators, economic indicators.

$$
\sum_{i=1}^{4} a_{i}=1
$$

\section{EXPERIMENTS AND RESULTS ANALYSIS}

Different modes of transportation of transport distance on the relationship between the cost have the certain differences. Such as railway transportation distance is much bigger than the size of the rising costs of increase, and the road, on the other hand. Fig. (3) expressed five kinds of the transportation cost change with the increase of transportation distance:

As shown in Fig. (4), $p_{0}$ point is distribution center. To deliver it to the user $p_{1}$ and $p_{2}$. Set the distance $p_{0}$ to $p_{1}$ and $p_{2}$ are $d_{01}$ and $d_{02}$. The distance between the two users is $d_{12}$. Delivery plan as shown in the two, respectively in the figure shown in (a) and (b):

Solution (a) is delivering from the distribution center to the user $\mathrm{p} 1$ and $\mathrm{p} 2$ respectively, and distribution route is as follows: $p_{0} \rightarrow p_{1} \rightarrow p_{0} \rightarrow p_{2} \rightarrow p_{0}$

The general distribution distance is:

$D_{a}=2 d_{01}+2 d_{02}$

Solution (b) is delivering from the distribution center to the user $p_{1}$ and $p_{2}$ at the same time and distribution route is as follows:

$$
\begin{aligned}
& p_{0} \rightarrow p_{1} \rightarrow p_{2} \rightarrow p_{0} \\
& p_{0} \rightarrow p_{2} \rightarrow p_{1} \rightarrow p_{0}
\end{aligned}
$$

The general distribution distance is:

$D_{b}=d_{01}+d_{12}+d_{02}$

Comparing the two scheme, take the best solution. Because the smaller distribution distance shows scheme more reasonable.

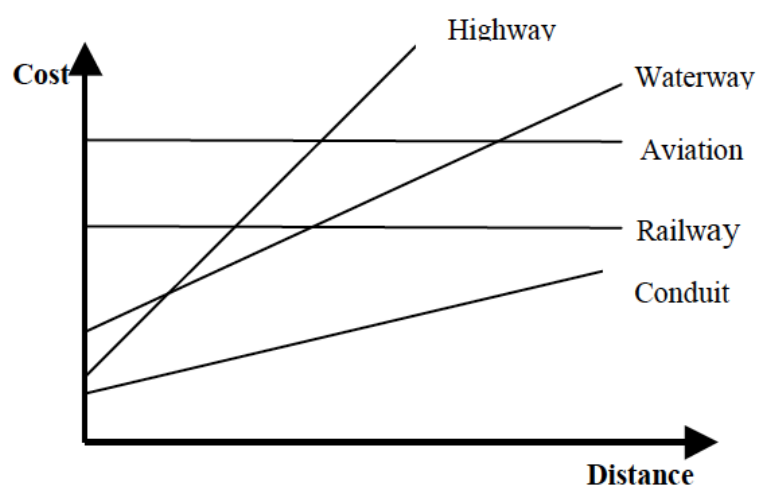

Fig. (3). Transportation costs vary with distance.

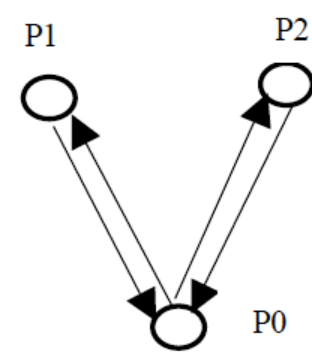

(a)

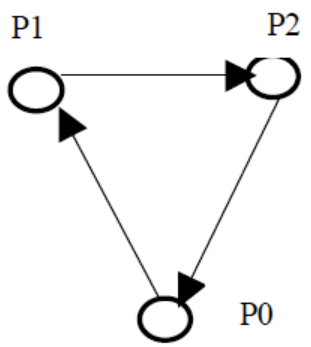

(b)
Fig. (4). Two kinds of transport scheme.

Fig. (5) is transportation decision-making cost comparison results, where abscissa is transportation distance, and the ordinate is cost. It shows that using neural network to make decisions, cost is less than that do not apply the neural network. Therefore, the proposed method is effective and feasible.

\section{CONCLUSION}

In China in a few years after the start, the third party logistics although has obtained certain achievements, but with the world's developed countries of the third party logistics development level have certain gap, the overall effect is not obvious. It Is mainly due to the third party logistics enterprises in our country are mostly from the original transporta- 


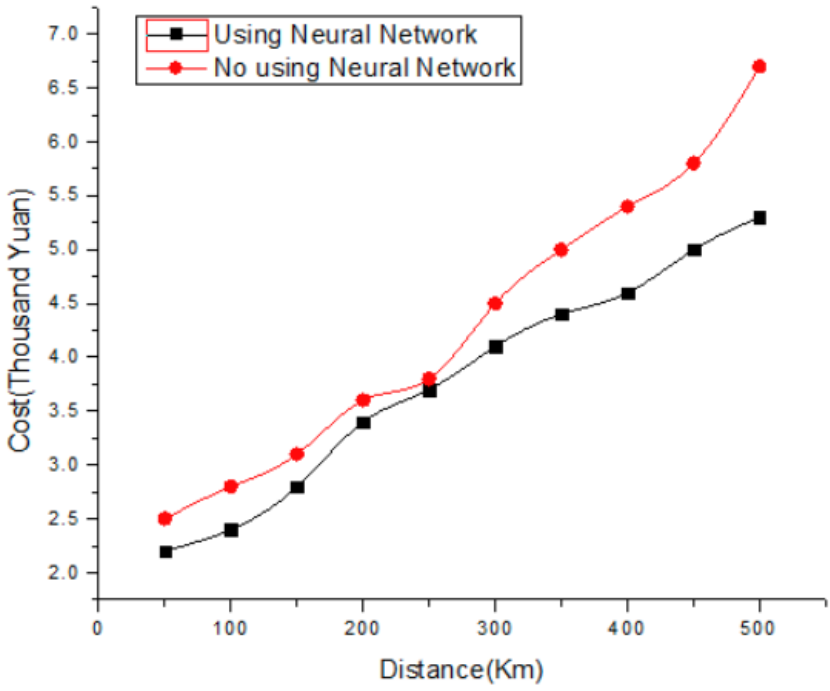

Fig. (5). Transportation decision-making cost comparison results.

tion or warehousing enterprise change, disadvantages with the understanding of modern logistics is more a lack of operation experience of modern logistics. In transportation decision-making, service is not a scientific phenomenon. Therefore, in view of the third party logistics transportation decision-making research in depth has very important practical significance.

On the basis of front, evaluation index of network transport if determined, as well as the optimization problem of transportation. Finally experimental results are presented, and the experimental results are analyzed. Experimental results show that the neural network can solve the transport problem, and it is very efficient.

\section{CONFLICT OF INTEREST}

The authors confirm that this article content has no conflict of interest.

\section{ACKNOWLEDGEMENTS}

This work is supported by National Natural Science Foundation of China (No. 71261005).

\section{REFERENCES}

[1] K. Cullinane, D. W. Song, and R. Gray, "Astochastic frontier model of the efficiency of major container terminals in Asia: assessing the influence of administrative and ownership structures," Transportation Research Part A, vol.36, pp. 743-762, 2002.

[2] D. R. Hull, "Aiming High: Competitive Benchmarking for Superior Performance", Lang Range Planning, pp. 39-44, 2010.

[3] G.B. De Wolf, "Process safety management in the pipeline industry: parallels and differences between the pipeline integrity management rule of the office of pipeline", Safety and the Distribution \& Logistics Management, vol.38, no.4, pp. 262-279, 2005.

[4] M. J. Farrell, "The measurement of productive efficacy", Journal of the Royal Statistical Society, vol.120, pp.125-281, 2007.

[5] S. E. Fawcett, and M. B. Cooper, "Logistics Performance Measurement and Customer Success-Industrial Marketing Management", pp. 341-357, 2009.

[6] G. Zack, "Maintaining the cold chain", International Journal of Control, vol.73, no.12, pp. 20-29, 2008.

[7] H. O. Fried, C. A. K. LoveIl, S. S. Schmidt, and S. Yaisawarng, "Accounting for environmental effects and statistical noise in data envelopment analysis", Journal of Productivity Analysis, vol.17, pp.157-174, 2011

[8] D. J. Aigner, C. A .K. Lovell, and P. Schmidt, "Formulation and estimation of stochastic frontier production fiction models", Journal of Econometrics, vol. 6, pp.21-37, 2012.

[9] A. C. F. Guimarees, and N. F. F. Ebecken, "FuzzyFAT: a fuzzy fault tree system for uncertainty analysis", Annals of Nuclear Energy, vol. 26, no.6, pp. 523-532, 2009.

[10] N.K. Avkiran, "Decomposing technical efficiency and window analysis", Studies in Economics and Finance, vol. 22, no.1, pp.6191, 2007.

(C) Huang Xianjun; Licensee Bentham Open.

This is an open access article licensed under the terms of the Creative Commons Attribution Non-Commercial License (http://creativecommons.org/licenses/by-nc/3.0/) which permits unrestricted, non-commercial use, distribution and reproduction in any medium, provided the work is properly cited. 